\title{
Using smartphone logging to gain insight about phone use in traffic
}

\author{
Christer Ahlström ${ }^{1,2}\left(\right.$ ] Jesper Wachtmeister ${ }^{3} \cdot$ Mattias Nyman $^{4} \cdot$ Axel Nordenström $^{4} \cdot$ Katja Kircher $^{1,5}(\mathbb{C}$
}

Received: 19 December 2018 / Accepted: 31 January 2019 / Published online: 13 February 2019

(c) The Author(s) 2019

\begin{abstract}
The prevalence of mobile phone usage in traffic has been studied by road-side counting, naturalistic driving data, surveillance cameras, smartphone logging, and subjective estimates via surveys. Here, we describe a custom-made smartphone logging application along with suggestions on how future such applications should be designed. The developed application logs' start and end times of all phone interactions (mobile phone applications, incoming/outgoing phone calls and text messages, audio output, and screen activations). In addition, all movements are automatically classified into transport, cycling, walking, running, or stationary. The capabilities of the approach are demonstrated in a pilot study with 143 participants. Examples of results that can be gained from smartphone logging include prevalence in different transportation modes (here found to be $12 \%$ while driving, $4 \%$ while cycling, and $7 \%$ while walking), which apps are being used (here found to be $19 \%$ navigation, $12 \%$ talking, $12 \%$ social media, and $10 \%$ games) and on which road types (rural, urban, highway etc.). Smartphone logging was found to be an insightful complement to the other methods for assessing phone use in traffic, especially since it allows the analyses of which apps are used and where they are used, split into transportation mode and road type, all at a relatively low cost.
\end{abstract}

Keywords Driver distraction $\cdot$ Mobile phone $\cdot$ Prevalence $\cdot$ Smartphone logging

\section{Introduction}

Information on how individuals move and interact in time and space has recently provided new insights about travel patterns and how they vary among populations, time, places, and social networks. Such data, which can now be logged directly from a smartphone, have been used to forecast future travel demands and aid infrastructure developments including strategies on how to move toward more sustainable modes of transportation (Bar-Gera 2007; Chen et al. 2016; Järv et al. 2012; Wang et al. 2012, 2018). Such data

Christer Ahlström

christer.ahlstrom@vti.se

1 Swedish National Road and Transport Research Institute (VTI), 58195 Linköping, Sweden

2 Department of Biomedical Engineering, Linköping University, 58183 Linköping, Sweden

3 Mobile Behaviour, 17893 Stockholm, Sweden

4 DING (Designingenjörerna Sverige AB), 11733 Stockholm, Sweden

5 Department of Behavioural Sciences and Learning, Linköping University, 58183 Linköping, Sweden have also proven to be useful in behavioural studies on social interactions and daily activities (Harari et al. 2017). The objective of this paper is to investigate how mobile phone data can be used to learn more about how road users interact with mobile devices in traffic. The long-term hope is that smartphone logging will provide knowledge about which smartphone applications are used when and where, so that targeted countermeasures can be designed to prevent dangerous use of mobile devices in traffic.

In driver distraction research, much effort has been dedicated to understanding the effects of talking and texting on driving (euroFOT 2011; Caird et al. 2018; Elvik 2011; Simmons et al. 2016; McCartt et al. 2006; Svenson and Patten 2005). However, much less is known about the other types of interaction with the phone, including listening to music, navigation, shopping, dating, taking pictures, watching movies, and playing games (George et al. 2018; Cunningham et al. 2017). These different activities vary enormously in terms of task completion time, visual engagement, psychological engagement, time pressure, and many other factors. An assessment of the impact of these activities on traffic safety necessitates knowledge about how often, when, and where a certain interaction is performed. Accurate information 
about prevalence figures can also guide research to the more pressing topics. For example, if smartphones are found to be extensively used for playing games or updating social media while driving, it may be a good idea to influence norms, so that this behaviour becomes socially unacceptable. On the other hand, if mobile phones are mostly used for navigation, it may be better to funnel research activities toward better HMI designs.

Traditionally, prevalence figures have been obtained via surveys (Olsen et al. 2013; Hill et al. 2015; Harrison 2011; Troglauer et al. 2006), by counting (Glassbrenner and Ye 2007; National Highway Traffic Safety Administration 2010; Vivoda et al. 2008; Taylor et al. 2007; Johnson et al. 2004; Wilkinson et al. 2015), and more recently, from naturalistic driving studies (NDS) (Olson et al. 2009; Klauer et al. 2014; Hickman et al. 2010). Another emerging technology is to use the mobile phones themselves as data loggers (Albert and Lotan 2018; Kujala and Mäkelä 2018; Oren et al. 2018), as presented and evaluated in the current paper. An overview of different methods to assess prevalence is provided in Table 1, which illustrates some of the advantages and disadvantages with the respective methods.

An inherent issue with self-reported prevalence is the difficulty of arriving at quantifiable figures. Response alternatives such as "often", "seldom", or "almost always" make it hard to estimate for how long the phone has been used. "Almost always" may, for example, be interpreted as "during almost every trip", or "almost all the time while I am sitting in the car". Asking instead how many times per trip or per hour of driving somebody uses a phone does not improve the situation much, as it is very difficult to make a good estimate, even with the best intentions. Not surprisingly, several studies show that self-reported behaviour does not necessarily correspond to the observed behaviour. For example, men report more frequent phone usage while driving, while naturalistic driving studies found that women use the phone more or at least as often as men while driving (Albert and Lotan 2018; Carney et al. 2015; Funkhouser and Sayer 2012).

In contrast to the self-reports, objective measurements are easier to quantify. However, observations in intersections or via surveillance cameras are limited to fixed locations, which may not be representative for phone interactions, in general. It has been shown that drivers adapt whether and how they interact with their phone to the suitability of the location (Huth and Brusque 2013; Dozza et al. 2013; Young 2015; Becic et al. 2010; Hickman and Hanowski 2012; Tivesten and Dozza 2015; Wandtner et al. 2016; Oviedo-Trespalacios et al. 2017). Such adaptations will, of course, affect prevalence figures obtained in a specific location. From NDS, continuous data from complete trips are available, but just as with road-side observations, the possibilities to differentiate between the usages of different applications are very limited, and hands-free interactions may not be picked up at all.

Logging smartphone data make it possible to analyse which apps are being used when and where. Lack of generalisability may be an issue, as frequent mobile phone users may choose not to participate if they are aware that their behaviour is socially less accepted and illegal. Two slightly different approaches have been presented for smart phone logging of mobile phone usage behaviour. Kujala and Mäkelä (2018) suggested a system where an additional mobile phone was installed in the participant's car, acting as a hotspot. The participant's phone then connected to the hotspot, and a custom-made application installed on the participant's phone, tracked screen touches, and logged the foreground application. The collected data also contained the current position, road type, and driving speed, logged via GPS with a frequency of $1 \mathrm{~Hz}$. Thus, data were

Table 1 Overview of different aspects of the traditional methods to obtain prevalence figures of mobile phone usage while driving

\begin{tabular}{|c|c|c|c|c|}
\hline & Survey & Counting & NDS & Phone logging \\
\hline Objectivity & Self-reported, subjective & $\begin{array}{l}\text { Observed, observer judge- } \\
\text { ment bias possible }\end{array}$ & $\begin{array}{l}\text { Observed, inter-rater reli- } \\
\text { ability testable }\end{array}$ & $\begin{array}{l}\text { Logged in phone, highest } \\
\text { objectivity }\end{array}$ \\
\hline $\begin{array}{l}\text { Representativeness of } \\
\text { participants }\end{array}$ & $\begin{array}{l}\text { Easy to access many partic- } \\
\text { ipants, self-selection bias }\end{array}$ & $\begin{array}{l}\text { Depend on observation } \\
\text { duration and traffic flow, } \\
\text { choice of location deter- } \\
\text { mines participation }\end{array}$ & $\begin{array}{l}\text { Limited number of par- } \\
\text { ticipants, self-selection } \\
\text { bias, depend on inclusion } \\
\text { method }\end{array}$ & $\begin{array}{l}\text { Large number of par- } \\
\text { ticipants possible, self- } \\
\text { selection bias, currently } \\
\text { only possible on more } \\
\text { "open" mobile phone } \\
\text { platforms, e.g. Android }\end{array}$ \\
\hline $\begin{array}{l}\text { Representativeness of } \\
\text { behaviour }\end{array}$ & $\begin{array}{l}\text { Inherently very difficult } \\
\text { to obtain objectifiable } \\
\text { information }\end{array}$ & $\begin{array}{l}\text { Behaviour may depend on } \\
\text { the counting location }\end{array}$ & $\begin{array}{l}\text { Representative, as logged } \\
\text { continuously while } \\
\text { driving }\end{array}$ & $\begin{array}{l}\text { Representative, as logged } \\
\text { continuously while driv- } \\
\text { ing or in general }\end{array}$ \\
\hline $\begin{array}{l}\text { Differentiation between } \\
\text { apps }\end{array}$ & $\begin{array}{l}\text { Possible in theory, but diffi- } \\
\text { cult to self-report }\end{array}$ & Very limited & Very limited & $\begin{array}{l}\text { Possible, with minor } \\
\text { limitations }\end{array}$ \\
\hline Costs & Somewhat costly & Somewhat costly & Very costly & $\begin{array}{l}\text { Cheap, once established, } \\
\text { user support may be } \\
\text { necessary }\end{array}$ \\
\hline
\end{tabular}


collected solely while driving in the vehicle instrumented with the additional phone, and it was not possible to distinguish whether the phone being logged belonged to the driver or the passenger in the car. Albert and Lotan (2018) suggested another approach, using an app from the company ProtextMe ${ }^{\circledR}$ (Ra'anana, Israel). This solution is based on an application installed on the participant's smartphone which monitors touches and the foreground application, along with position and speed, when the GPS is turned on. Driving is detected by analysing the GPS signal, by the activation of navigation applications (like Waze ${ }^{\circledR}$ or Google Maps ${ }^{\circledR}$ ), or by connection to an optional near-field sensor or beacon mounted in the car. It is assumed that the phone owner is driving, but it is possible to indicate that this is not the case by actively selecting an alternative in the app; for example "passenger" or "riding a bus". In addition, Oren et al. (2018) have presented a solution based on ProtextMe ${ }^{\circledR}$, but they used it in combination with another application which identified driving events.

In this paper, an alternative method of mobile phone logging is presented, which allows phone usage monitoring around the clock; that is, data are not only collected while driving, but also while using the other modes of transport and when stationary, for example when the phone owner is at home or at work (i.e., when not in transport). The intention is to increase knowledge about the prevalence of application usage in different contexts, which also allows the assessment of context specificity. To enhance this further, where applicable, the logged phone usage data are complemented with road type and speed limit in a post-processing stage.

The aim of this paper is to evaluate phone logging as a method to assess smartphone use in traffic, to highlight the pros and cons of different approaches, and to discuss requirements and improvement suggestions for future development. Data from a pilot study in Sweden are presented as the initial proof of the proposed method, to exemplify its application, and to identify areas for improvement.

\section{The phone logging application}

Phone usage is logged with an in-house custom-made application called Apparat-VTI (Mobile Behaviour, Stockholm, Sweden), which is linked to a commercial application called Moves ${ }^{\circledR}$ (Facebook Inc., California, US). At the time of the study, both applications were available on GooglePlay ${ }^{\circledR}$, but, since then, the Moves application has shut down.

The Apparat-VTI application is running in the background and stores interactions with the phone (Fig. 1). This includes the phone's brand and model, the type of network used (EDGE, GPRS, HSPA, LTE, UMTS, WIFI, etc.), whether a network is available, which application is used, the start and end times when the application is active,

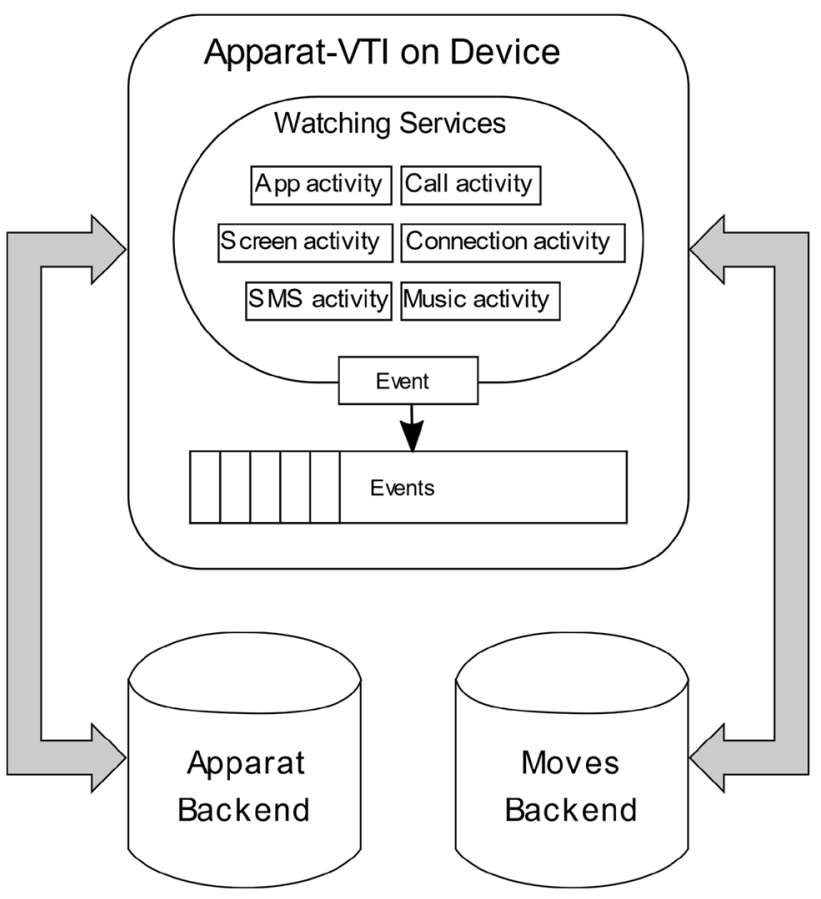

Fig. 1 Schematic illustration of the data flow in the Apparat-VTI app. Activities that are detected by the watching services are stored in an internal data structure called an Event. All events are queued up and sent to the Apparat backend three times a day. Data from the Moves application are synchronized via the Moves Backend, which the Apparat-VTI application has access to

start and end times of incoming/outgoing SMS/MMS/calls, whether sound is on or off, and whether the screen is on or off. Only the names of the applications are stored, not the internal state or the content. This means that webpages that the participants visit, text that is entered, etc., are not stored. All communications between the device and the Apparat server uses the Secure Sockets Layer (SSL) protocol, and the only link between the collected phone usage data and the user is an e-mail address, which is encrypted and stored in a separate database.

To be able to monitor user interactions with the phone, the Apparat-VTI application employs a series of watch services. Separate services are used to monitor application activity, call activity, connection activity, screen activity, text message activity, and music activity. In some cases, there are several implementations of each service to ensure compatibility with different versions of the smartphone operating system (Android). Each service continuously stores information about the activities in an internal data format that is called an "event". All events are sent to, managed, and stored locally on the device by an "Observing Meta Service".

For each application activity, Apparat-VTI stores a unique event id along with the user id, the type of activity, the name of the application, start time, and end time. A screen event 
starts when the screen is unlocked, and it ends either when the user locks the screen, or when it goes to sleep. The start time of an application is set when it is put into the foreground, either via unlocking the screen or when starting the application. The corresponding end time is either when the screen turns off or when the application is sent to the background. A music event is logged when the audio output of the device is active, and, thus, also includes podcasts, audiobooks, etc.

To link phone usage behaviour to GPS position, ApparatVTI is linked to the Moves application. Data are synchronized between the two applications via the Moves backend (Fig. 1). The Moves application stores the user's latitude and longitude together with timestamps. Based on these data, Moves cluster the coordinates into trips and classifies the trips as transportation, cycling, running, walking, or stationary. Note that stationary, which is defined as not moving, for example when at work or at home, is included for comparison, even though it is not an actual transportation mode. A drawback with Moves is that GPS data are stored only occasionally during movement, and not at all while stationary, to reduce battery consumption. This means that GPS data are stored irregularly and with low sample rate. In practise, this means that, for some trips or segments within a trip, the sample rate could be $1 \mathrm{~Hz}$, while, on other trips, a person can travel several city blocks between two sample points.

At least three times a day, logged events are sent to the Apparat backend, where they are stored in a database (MySQL Community Edition ver. 14.14, Oracle Corporation, California, US). Events that are successfully uploaded to the server are removed from the device. If data are not successfully uploaded to the server, the application automatically stores the events in a queue and tries to upload them again within an hour.

Apparat-VTI includes the possibility to ask the phone owner for off-line annotations of trips, like indicating whether one had been driver or passenger, and which type of motor vehicle had been used. It is also possible to send push messages with information or questionnaires if desired.

\section{Methods evaluation}

A pilot study was conducted with a convenience sample consisting of 143 participants (53 women) who were recruited via letters, Facebook, a participant portal at VTI, and through local media. Their mean age was $38.4 \pm 13.1$ years. The requirements for participation were the possession of a valid driver's license and an Android smartphone. Each participant contributed with data for between 3 and 10 weeks. After the study, each participant received a cinema ticket and a personalised phone usage report. Data were collected from December 2016 to February 2017. At the time of the study, there were no specific laws prohibiting mobile phone use while driving or cycling in Sweden. However, the general law against reckless driving applied, along with an amendment that it is only allowed to use communication devices while driving a motorized vehicle if it does not have a negative impact on driving safety.

Given the diversity of when and how a phone can be used, this is a small data set. The results presented in this section should not be generalised outside the study population. They are included here to demonstrate the potential usefulness of naturalistic phone usage logging and to exemplify and discuss possible analyses, rather than to present representative numbers of true phone usage.

Three post-processing steps were used to enrich the data that were obtained from the Apparat-VTI app. First, all trips were corrected and annotated by the phone owners. Each evening at 20:00, a push message was sent to their device, asking the user to check the movement classifications. A typical example of a misclassification is fast cycling, which Moves could interpret as a motor vehicle trip. After the manual corrections, the user was asked whether he/she was the driver or the passenger on each event marked as "transport", with which type of vehicle which the trip had been conducted (car, truck, bus, train, or other), and whether it was a private or a professional trip. Second, all application names were automatically categorised according to the list of categories for applications and games that is provided by Google. Third, all the stored GPS coordinates were enriched with road type and speed limit using map data from OpenStreetMap ${ }^{\circledR}$. An extract of Sweden was downloaded in February 2017 and imported in a PostgreSQL database (version 9.2.13) using Osmosis (version 0.40.1). A query was then made for every logged GPS coordinate to fetch the map object with the minimum two-dimensional Cartesian distance from the PostgreSQL database.

Entire car and truck trips with a mean speed below $10 \mathrm{~km} / \mathrm{h}$, and bicycle and walking trips with a mean speed below $1 \mathrm{~km} / \mathrm{h}$, were excluded from further analyses, as they were considered unrepresentative and possibly flawed. Car and truck trips where the user had been passenger were also excluded. This resulted in a data set with 33,946 h of phone usage data, including 4219 car trips $(1336 \mathrm{~h}, 55,840 \mathrm{~km})$, 51 truck trips $(19 \mathrm{~h}, 1150 \mathrm{~km}), 655$ bicycle trips $(156 \mathrm{~h}$, $1780 \mathrm{~km})$, and 21,423 walking trips (1422 h, $5430 \mathrm{~km})$. Car and truck trips were merged into a car/truck category due to the small number of truck trips. The data were analysed per trip, per transport mode, and per road type.

Phone usage has been categorised as Talking, Texting, Apps, and Not active. Talking is when the phone is used for regular phone calls. Voice over IP services are not in the Talking category. Texting is when the phone is used for text messaging, including ordinary SMS/MMS as well as the most common messaging applications such as Messenger, 
Snapchat, WhatsApp, and Kik. Apps are when other applications except the ones included in the Talking and Texting categories are used. Not active is the remaining time when the user is not interacting with the phone.

\subsection{Prevalence of phone usage}

Figure 2 shows the prevalence of phone usage per transportation mode. In general, it is much more common to use applications than to talk or send text messages. When driving, people interacted with their phones about $12 \%$ of the time, which is not much less than while stationary (16\%). The percentage of trips during which users interacted with their phone at least once was $47.1 \%$ for driving, $19.2 \%$ for cycling, and $22.0 \%$ for walking. Women $(49.6 \%)$ used their phones during more driving trips than men $\left(44.9 \%, \chi^{2}=7.8\right.$, $p<0.05$ ), but there were no consistent trends related to sex or age that persisted across categories and transportation modes.

It was more common to use the phone on longer trips. The average trip when the phone was used at least once was $18 \mathrm{~km}$ (34 min), compared to $9 \mathrm{~km}$ (15 min) when the phone was not used. It was also more common to use the phone during daytime (09:00-15:00) and during the afternoon (15:00-18:00) than during the evening (18:00-23:00), during the night (23:00-07:00), and during the morning rush hour (07:00-09:00). For driving, there was no difference between days of the week, but while cycling or walking, it was less common to use the phone during weekends. Detailed information about how the phone was used for calling, texting, listening to music, and using other applications was analysed, which is presented below.

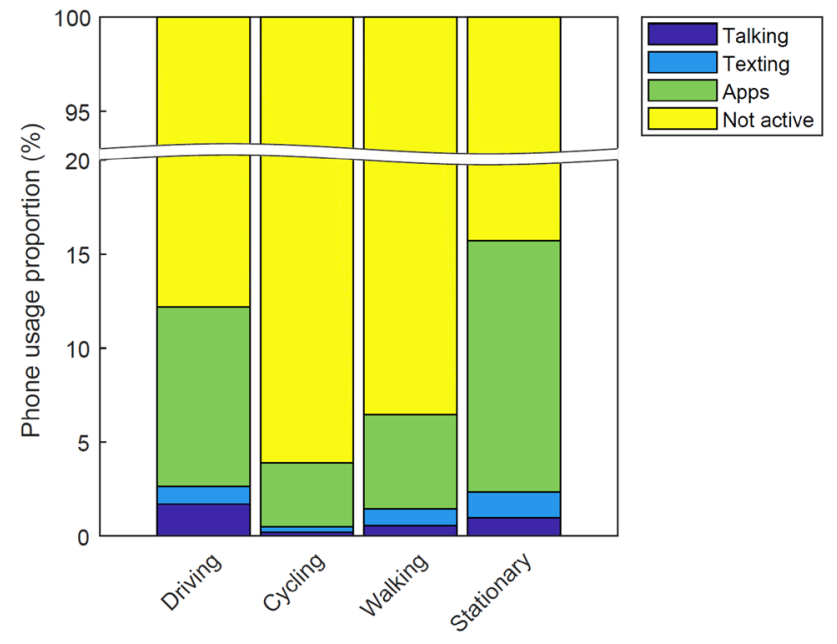

Fig. 2 Proportion of time that the phone was used per transportation mode. In "stationary", the category not active was removed if it had a duration $>6 \mathrm{~h}$, of which $>4$ h occurred between 22:00-08:00 (presumed sleep)
Talking: Car drivers were called at least once in 3.8\% of the trips, whereas they made outgoing calls in $8.4 \%$ of the trips. On average, the users talked on their phone every 35 th min while driving. The median duration of incoming phone calls was $2.4 \mathrm{~min}$ and $1.7 \mathrm{~min}$ for outgoing phone calls. This is comparable to the mean phone conversation duration of 2.6 min reported for a naturalistic driving study (Funkhouser and Sayer 2012). On the motorway and the rural road, $64 \%$ and, respectively, $62 \%$ of the phone conversations were longer than $1 \mathrm{~min}$, whereas, on urban roads, that number was $51 \%$.

Texting The car drivers sent or received at least one text message in $8.4 \%$ of the trips. There were about twice as many incoming as outgoing text messages while driving. The median duration of a text messaging session was $36 \mathrm{~s}$. The probability of sending a text message increased if it was preceded by an incoming message and vice versa, indicating that text messages are not only used for unidirectional information, but also for conversations. That said, 55\% of all trips with at least one texting event contained only one message. Only about $20 \%$ of these messages were outgoing. This means that it is quite common that a driver receives a text message without responding to it.

Music It was not very common to listen to music via the phone while driving. Only in $18 \%$ of the trips the phone was used to play music, and in only $5 \%$ of the trips, the phone was used to play music during more than $80 \%$ of the trip. For cycling and walking, the phone was used to play music in only $4 \%$ and $2 \%$ of the trips, respectively.

Apps The most common application category used while driving consists of transportation applications, followed by talking (Fig. 3; Table 2). The categories social media, games, browsing, and media sum up to about $40 \%$ of the time during which participants used their phone while driving. In comparison, more than $50 \%$ of the time which cyclists interact with their phone was spent on location-based games such as Turf and Pokémon Go. Unfortunately, from the logged data, it is not discernible how many bike trips were made solely for the purpose of gaming. When stationary, transportationrelated applications were not used as frequently. Instead, the participants were mainly engaged in social media and web browsing.

\subsection{Application usage per road type}

When driving, it was more common to use the phone on the motorway than on rural and urban roads. The distribution between different application categories per road type is presented in Fig. 4. The most striking result is that games were much more commonly used in urban environments. 


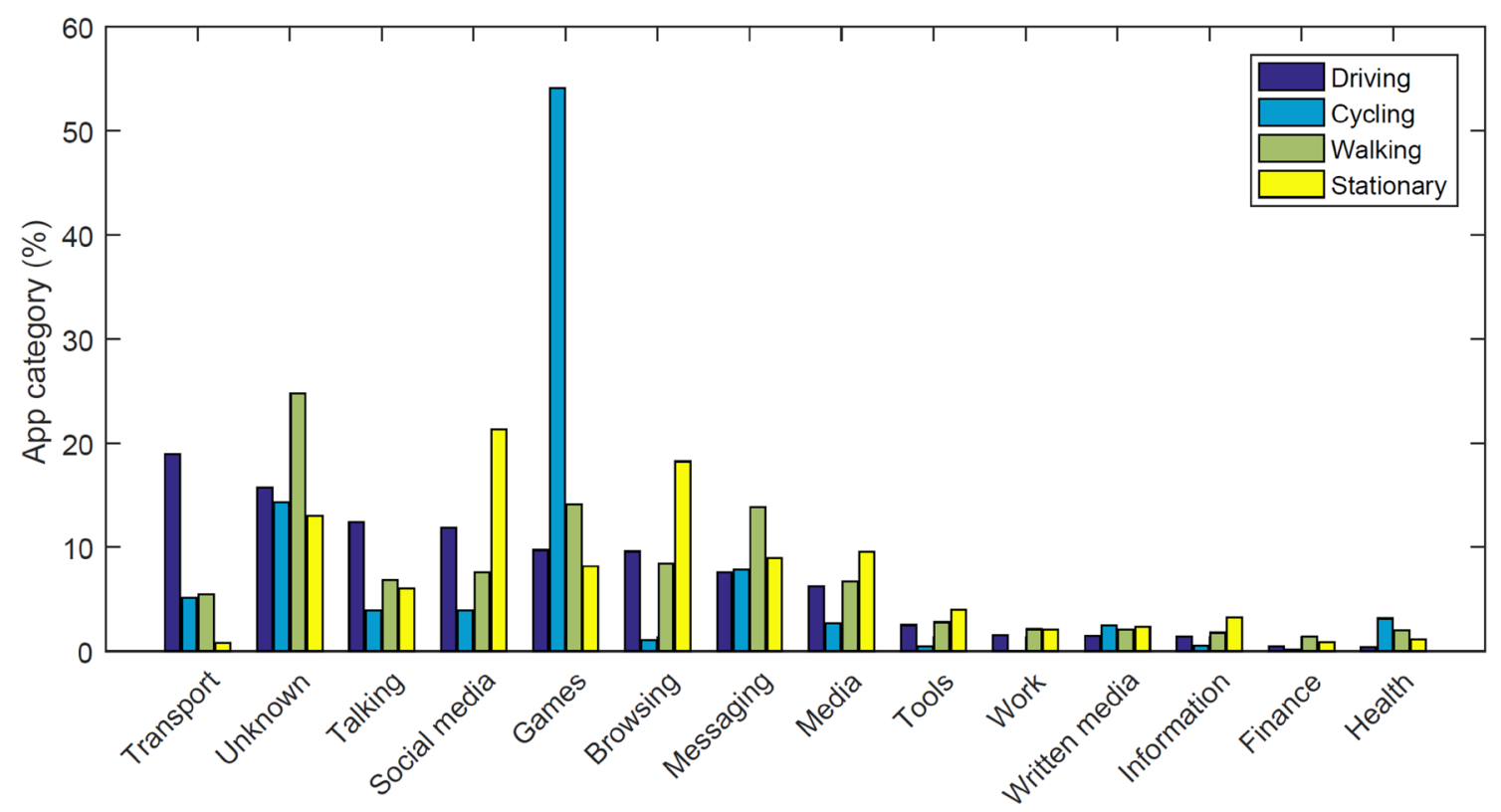

Fig. 3 Distribution of different application categories by transportation mode. The categories are sorted in descending order based on driving trips

The by-far most frequently used game in the urban environment was Pokémon Go (Table 2), which only works at speeds below $18 \mathrm{~km} / \mathrm{h}$ (this result obviously reflects the time period when the data were collected, and should be seen as an example of any popular location-based game). On motorways and on rural roads, it was more common to talk on the phone and to use social media applications. Work-related applications were used more frequently on urban roads and on motorways, but not so much on rural roads.

\subsection{Method evaluation discussion}

The results showed that the phone was used for $12 \%$ of the driving time, a figure that is comparable to the results of Funkhouser, Sayer (Funkhouser and Sayer 2012), but higher than the 3.5 min of phone usage per hour driven found in the Zendrive study including 3 months of data from 3 million anonymous drivers (Scott 2017). The previous research has shown that drivers initiate cell-phone conversations more frequently during low-speed conditions (Funkhouser and Sayer 2012) and also that visual-manual phone tasks are often initiated while stationary (Funkhouser and Sayer 2012; Tivesten and Dozza 2015). Our findings complement such results with which applications are used where, see Sect. 3.2. For example, social media applications were used more often on motorways and rural roads than on urban roads. While such a finding corroborates the idea that drivers tend to use their phones in less demanding driving environments (Parnell et al. 2018; Zhou et al. 2016), we can see that the other attention demanding applications such as browsing the web or using different media applications were about equally frequent in all the environments. Unfortunately, the sample rate problem described in Sect. 2 made it impossible to check whether these interactions occurred while standing still, for example at a red light in an urban environment. With a higher sample rate, such analyses would have been possible.

Interestingly, outgoing phone calls were more frequent than incoming phone calls, across all transportation modes. This indicates that drivers see the time which they spend during transport as "time available" to get things done and to manage their social contacts. However, they seem to prefer having longer conversations outside of urban areas.

Drivers were texting in about one out of ten trips. In more than half of the cases, this involved reading a single incoming text message. The probability to send a text message increased after first having received a text message, leading to a texting conversation. This means that a driver who does not receive a text message is less inclined to write a text message than a driver who has received an incoming text message. This indicates that an intelligent task manager that blocks or delays incoming messages to low-complexity situations could be an effective countermeasure.

As already mentioned, the results presented in this section should not be generalised outside the study population. Several difficulties arise when using a convenience sample. For example, it is likely that the participants who volunteer to take part of the study either do so, because they are interested in the subject matter, because they are eager to receive the incentive, because they want to show that they 
Table 2 The most commonly used applications in the most common categories, per transportation mode

\begin{tabular}{|c|c|c|c|c|}
\hline & Driving & Cycling & Walking & Stationary (not in traffic) \\
\hline \multirow[t]{5}{*}{ Transport } & Maps $46.1 \%$ & Maps $82.4 \%$ & Maps $73.8 \%$ & Maps $51.8 \%$ \\
\hline & Waze $33.1 \%$ & EasyPark $11.8 \%$ & EasyPark 5.4\% & STHLM Traveling 3.8\% \\
\hline & Navmii $6.0 \%$ & irezQ $5.9 \%$ & Res i Sthlm $4.0 \%$ & EasyPark $3.7 \%$ \\
\hline & irezQ $2.3 \%$ & & Reseplanerare $3.5 \%$ & Waze $3.7 \%$ \\
\hline & STHLM Traveling $1.7 \%$ & & STHLM Traveling $2.1 \%$ & SAS $3.0 \%$ \\
\hline \multirow[t]{5}{*}{ Social media } & Facebook $62.1 \%$ & Instagram $68.4 \%$ & Facebook $66.3 \%$ & Facebook $62.8 \%$ \\
\hline & Instagram $21.0 \%$ & Facebook $21.1 \%$ & Instagram $20.8 \%$ & Instagram $17.8 \%$ \\
\hline & Twitter $3.5 \%$ & Twitter $10.5 \%$ & Twitter $4.1 \%$ & Twitter $3.6 \%$ \\
\hline & Couple $2.9 \%$ & & Groups $3.6 \%$ & Swipe Pro $2.3 \%$ \\
\hline & InstaRepost $2.4 \%$ & & Tapatalk $1.1 \%$ & Tapatalk $1.8 \%$ \\
\hline \multirow[t]{5}{*}{ Games } & Pokémon GO $60.0 \%$ & Turf $58.2 \%$ & Pokémon GO $64.7 \%$ & Pokémon GO 33.1\% \\
\hline & Turf $16.0 \%$ & Pokémon GO 38.8\% & Turf $13.8 \%$ & Wordfeud $10.6 \%$ \\
\hline & Quizkampen $4.5 \%$ & Wordfeud $3.1 \%$ & Wordfeud $6.4 \%$ & FFEXVIUS 5.4\% \\
\hline & NDS Boy! 4.3\% & & FFEXVIUS 5.5\% & Turf $5.3 \%$ \\
\hline & Backpacker $2.3 \%$ & & vHack $2.3 \%$ & Quizkampen $4.6 \%$ \\
\hline \multirow[t]{5}{*}{ Browsing } & Chrome $46.7 \%$ & Gmail $28.6 \%$ & Chrome $51.7 \%$ & Chrome $56.4 \%$ \\
\hline & Internet $16.6 \%$ & Firefox $23.8 \%$ & Gmail $21.5 \%$ & Gmail $16.6 \%$ \\
\hline & Gmail $15.4 \%$ & Contacts $19.0 \%$ & Truecaller $6.8 \%$ & Internet $9.2 \%$ \\
\hline & Truecaller $8.8 \%$ & Chrome $14.3 \%$ & Internet $5.0 \%$ & WhatsCall 3.9\% \\
\hline & $1802.9 \%$ & Ska jag svara? $9.5 \%$ & Firefox $4.9 \%$ & Truecaller $3.6 \%$ \\
\hline \multirow[t]{5}{*}{ Media } & Spotify $54.1 \%$ & Spotify $38.7 \%$ & Kamera $38.3 \%$ & Kamera $24.6 \%$ \\
\hline & Kamera $16.1 \%$ & Kamera $32.3 \%$ & Spotify $21.5 \%$ & YouTube $12.3 \%$ \\
\hline & YouTube $6.5 \%$ & Album $12.9 \%$ & Podkicker Pro 5.3\% & Spotify $10.5 \%$ \\
\hline & TuneIn Radio $4.8 \%$ & Mixcloud $12.9 \%$ & Fotoredigerare $4.7 \%$ & Netflix $5.4 \%$ \\
\hline & Album $1.9 \%$ & Podkicker Pro $3.2 \%$ & BitX $4.3 \%$ & Album 5.2\% \\
\hline \multirow[t]{5}{*}{ Health } & Endomondo $52.3 \%$ & Runkeeper $86.2 \%$ & Runkeeper $38.4 \%$ & Moves $25.0 \%$ \\
\hline & Moves $19.7 \%$ & Endomondo $6.9 \%$ & Moves $19.9 \%$ & Runkeeper $12.8 \%$ \\
\hline & Connect $3.8 \%$ & Moves $3.4 \%$ & Connect $13.9 \%$ & Lifesum $8.5 \%$ \\
\hline & PregLife $3.8 \%$ & S Health $3.4 \%$ & Endomondo $7.5 \%$ & S Health $8.2 \%$ \\
\hline & S Health $3.0 \%$ & & MyFitnessPal 3.8\% & Strava $7.2 \%$ \\
\hline
\end{tabular}

Some of the applications are specific for Sweden

can manage to use their phone while driving, or perhaps the opposite, that they want to show how dangerous it is. In combination with the sample rate issue, this method evaluation should be seen as a demonstrator of what mobile phone logging can be used for.

\section{Discussion}

\subsection{Comparison with other methods}

Compared to NDS and observational studies, logging behaviour via an application on the participant's phone is considerably cheaper, probably in the cost range of a survey once the application is developed and functional. This requires that the user interface is well designed to minimize the need for support. Despite the progress being made in automatic video analyses, NDS data still require considerable efforts in terms of manual video encoding. In comparison, the analyses of phone usage data collected via the phone is straightforward and can be automated. Streamlining the analyses is important, because it allows large data sets to be processed in full. This is in contrast to NDS where it is common to draw a sub-sample of the collected data for detailed analyses, meaning that results may vary considerably with the sampling procedure (Carsten et al. 2013).

The data obtained about driving behaviour are much less detailed than in NDS, both in frequency, in accuracy, and in the number of variables collected. During the pilot study described above, several possibilities for improvement were identified (see below), but the data richness obtained in an instrumented vehicle can never be reached. Compared to road-side observations, the data are richer in the sense that they are collected in more than one or a few locations, and in 


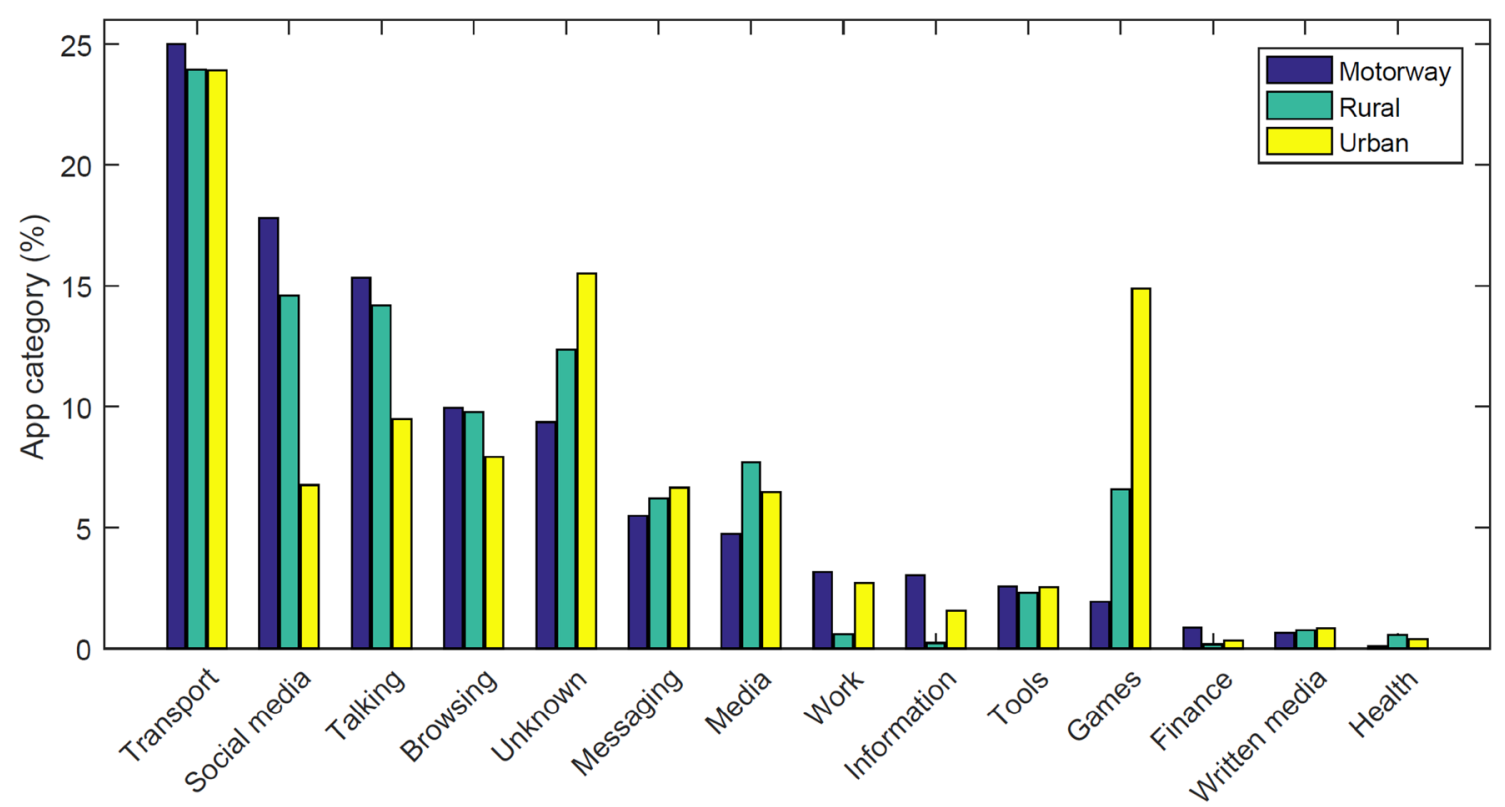

Fig. 4 Distribution of different application categories by road type. Only data from the transport mode "driving" are included

addition, they are obtained continuously for the same driver. However, in a road-side study, notes can be made about the traffic situation in a specific location, while, in phone-based logging, it is difficult to obtain any information about surrounding traffic on more than a very aggregated level, like the level of service of the road. Compared to a survey, the biggest difference is that phone and application usage is logged objectively, while the strength of a survey lies in the possibility to assess opinions about and attitude towards phone use in traffic.

It is a major drawback that phone logging does not allow studies on driver adaptation, since no information about the surrounding environment is available. NDS are favourable in this respect. A rudimentary improvement could be to $\log$ speed whenever position is logged, and to log both speed and position whenever an interaction with the phone is started or stopped, or even better, to sacrifice battery life and log position and speed continuously. This could give an indication of whether certain applications are used more frequently while stopped during a transportation trip. In addition, where available, it can be tried to obtain additional information about the surroundings from external databases, or from traffic-related applications. This could be traffic counts, weather-related data, traffic jams, etc. Access to the on-board diagnostics port (OBD2) of the car would allow the collection of driving-related data with much greater detail, but would require an additional equipment.

In purely phone-based logging, as with Apparat-VTI, it is possible to monitor phone usage behaviour around the clock, whenever the phone is on, offering the possibility to compare phone usage behaviour while driving with usage behaviour in the other modes of transportation, or when stationary. This is, as far as we know, unique for the ApparatVTI application. Knowing whether people use their smartphone in a different way while driving than when stationary or while cycling allows studying user needs and adaptations in a much more sophisticated manner, such that need-based applications can be developed and countermeasures against possible misuse can be targeted more efficiently.

The connection with the Moves application, especially in combination with the possibility to correct the misclassifications of transport mode manually, renders mode classifications acceptably reliable. If the phone-based logging needs external devices, like near-field sensors, beacons, and similar, the logging may be limited to in-car use, such that a comparison with out-of-car behaviour may not be possible. In general, the more additional equipment is needed, the more complicated it is to recruit participants and to set up the logging environment without personal contact.

The logged data on phone usage are much more detailed than what can be obtained with any other method. This is an important feature given the diversity of applications available on a modern smartphone. It matters whether the driver uses a navigation application or watches a movie; therefore, it is nowadays almost a necessity to be able to differentiate between different applications.

Apparat-VTI, just as ProtextMe, cannot be used on Iphones, as Apple does not support applications that log user behaviour as done here. This is a limitation, especially in countries with a high frequency of Iphone users, as it has been shown that their demographics and phone usage behaviour differ somewhat from that of Android phone users 
(Davidsson et al. 2016). Currently, it is not either possible to log usage of so-called floating widgets, like Facebook Messenger. Thus, if the phone owner uses such applications, the log data are not completely accurate.

Like in any study with recruited participants, it is possible that people change their behaviour systematically when being monitored, and the risk for that may increase, if the activity is less socially acceptable, like using the phone while driving. Depending on the type of study and the setup, the reminders of being monitored are of different strength. For phone-based logging, daily requests to identify whether one has been driver or passenger will increase awareness of being monitored, but will also enrich the data. In NDS, visible instrumentation in the car may increase awareness, while road-side observation is most likely not even noticed by the drivers passing by.

Finally, the fast pace with which applications are being developed can make research appear to lag. In the current data set, this becomes clearly apparent in the usage frequency of Pokémon Go. Therefore, it is important to present results in a more generic format than based on application names - a categorisation into classes is one option; another possible option is to sort applications according to the need of urgency to answer/interact, the typical interaction time, etc.

\subsection{Ethical considerations}

Participation is voluntary, and the participants install the application themselves, including explicitly accepting its functionality, which makes them aware of being monitored. No content of what is done within the applications selected by a participant is tracked. However, in countries where phone use while driving is prohibited, a potentially illegal behaviour is monitored and logged. This may jeopardise the participants' integrity. In addition, even though the content is not monitored, the mere activation of certain applications allows conclusions about a participant's behaviour and attitude. This may not be completely obvious for participants, even though spelt out in an informed consent form.

With the present setup, the Apparat-VTI application logs information about the smartphone model, but does not identify the specific smartphone. That is, it does not record the serial number or smartphone number. Apparat-VTI is able to see the IP address, but it does not store it.

The more specific the collected data are, the more useful it is for research purposes. At the same time, this jeopardises the privacy of the participants more. Anonymization is only partially possible, especially if GPS tracking is used in a naturalistic setting, as most people often return to their home in the end of the day. Thus, the identity of a person can, at least, be narrowed down to a small group of people. This, in combination with the usage of specific applications, may allow conclusions about sensitive information like faith, sexual orientation, or political views. Therefore, the researcher must make sure to obtain ethical approval for conducting such a study, but he or she must also take responsibility when reporting the data. The level of aggregation must be high enough to make, sure that no personal information is disclosed.

\subsection{Future research and development}

For large-scale studies, several improvements of the described approach would be desirable. Detailed analyses of speed and location, such as analyses of phone usage during peak-hour congestions or while standing still in an intersection, were prevented by the low sampling rate in Moves. Even though this is a deliberate trade-off between accuracy and battery consumption, future smartphone logging should sacrifice battery life to get more frequent location data. A compromise could be to increase the location data logging frequency whenever the phone is being charged. Furthermore, the transportation mode classifications in Moves should be improved, or a better classification algorithm has to be employed. Here, misclassifications were corrected manually by the user, but this is not a satisfactory solution in large-scale deployment. All in all, the present setup would be much improved if the Apparat-VTI app had logged GPS information on its own and had only used Moves for the movement classification.

The users also had to manually fill in whether they had been the driver or the passenger. Before large-scale deployment of smartphone logging, the correctness of these annotations should be investigated to get a better view on the accuracy of the collected data. Depending on the purpose of the study, this has then to be weighed against the fact that manual annotation constantly reminds the participant of being monitored.

It would be valuable to know whether the phone was used in hands-free or handheld mode. Scanning for connected Bluetooth devices may give a hint in this respect. In the current setup, the phone is logged as being used as soon as the screen is active, even though it is possible that the driver puts it away temporarily in a situation with high workload. As an improvement, it should be considered to log screen touches, as well, and possibly to use face recognition features for an assessment of whether the phone is being handled, looked at, or none of the two. Software capable of doing so is already available (e.g., Sentiance, Belgium).

Given the fast development of mobile devices such as smart watches and wearables, it would be desirable to log interaction with those devices, as well, to get a complete picture.

A combination of NDS and phone-based logging would be an interesting way forward, where video from NDS can 
be used for contextual information, and data from phone logging can be used as event markers for the video analyst. The phone data also provide enrichment of the naturalistic data, providing insight into what the driver is doing with the phone.

The presented pilot study demonstrated the unique possibilities of phone-based logging, including the examples of how these data can be used to analyse where and when the mobile phone is used to do what. This provides important information concerning adaptive and self-regulating behaviour when integrating mobile phone use with the driving task. Such knowledge could be used to design countermeasures that are both efficient and accepted by the users. For example, applications designed according to the dissonance engineering principles (Vanderhaegen and Carsten 2017), taking compensatory beliefs (Zhou et al. 2016) and cognitive dissonance (Atchley et al. 2011) into account, could adapt, block, or delay functionalities and incoming communications in a user-oriented, transparent, and even appealing manner to achieve beneficial results. If this is not done properly, countermeasures may lead to unwanted and unforeseen behaviours, such as when legislation led texting drivers to hide their phones from view to avoid fines (Highway Loss Data Institute 2010), or when the introduction of automated functionality led to an increased likelihood that drivers engage with secondary tasks (Strayer et al. 2003). Such unforeseen rules or mental models could perhaps be avoided if the countermeasures are designed to encourage and amplify good behaviours. Mobile phone logging could then be used to explore and discover such wanted behaviours.

\section{Conclusions}

None of the phone-based logging solutions available today provides the data richness and resolution that would be desirable for a substantial leap in data acquisition of mobile phone usage, even though several are promising, and they have their strengths in different areas. Thus, a combination of different logging applications, possibly in connection with vehicle instrumentation in the style of a naturalistic driving study, could lead to considerable improvements in the field. The main advantage with phone logging is that it is a cost-effective method to acquire detailed information about how the phone is used, and that it does not only work in one instrumented vehicle, but can follow a user across all the transportation modes as well as while stationary. Detailed data about phone usage in different modes of transportation are not only valuable for knowledge enhancement and understanding road users' strategies in handling their phones, but can also be used as a basis to build acceptable solutions to support users in safe usage of communication devices in traffic.

Acknowledgements We thank the Swedish Transport Agency for the financial support of this study.

Open Access This article is distributed under the terms of the Creative Commons Attribution 4.0 International License (http://creativeco mmons.org/licenses/by/4.0/), which permits unrestricted use, distribution, and reproduction in any medium, provided you give appropriate credit to the original author(s) and the source, provide a link to the Creative Commons license, and indicate if changes were made.

\section{References}

Albert G, Lotan T (2018) How many times do young drivers actually touch their smartphone screens while driving? IET Intell Transp Syst 12(6):414-419. https://doi.org/10.1049/ietits.2017.0208

Atchley P, Atwood S, Boulton A (2011) The choice to text and drive in younger drivers: behavior may shape attitude. Accid Anal Prev 43(1):134-142

Bar-Gera H (2007) Evaluation of a cellular phone-based system for measurements of traffic speeds and travel times: a case study from Israel. Transp Res Part C 15(6):380-391

Becic E, Dell G, Bock K, Garnsey S, Kubose T, Kramer A (2010) Driving impairs talking. Psychon Bull Rev 17(1):15-21. https:// doi.org/10.3758/PBR.17.1.15

Caird JK, Simmons SM, Wiley K, Johnston KA, Horrey WJ (2018) Does talking on a cell phone, with a passenger, or dialing affect driving performance? An updated systematic review and metaanalysis of experimental studies. Hum Factors 60(1):101-133

Carney C, McGehee DV, Harland K, Weiss M, Raby M (2015) Using naturalistic driving data to assess the prevalence of environmental factors and driver behaviors in teen driver crashes. AAA, Foundation for Traffic Safety, Washington

Carsten O, Kircher K, Jamson S (2013) Vehicle-based studies of driving in the real world: the hard truth? Accid Anal Prev 58(0):162174. https://doi.org/10.1016/j.aap.2013.06.006

Chen C, Ma J, Susilo Y, Liu Y, Wang M (2016) The promises of big data and small data for travel behavior (aka human mobility) analysis. Transp Res Part C 68:285-299

Cunningham ML, Regan MA, Imberger K (2017) Understanding driver distraction associated with specific behavioural interactions with in-vehicle and portable technologies. J Aust Coll Road Saf 28(1):27

Davidsson P, Olle F, Ahlgren M (2016) Svenskarna och Internet: Undersökning om svenskar-nas internetvanor [The Swedes and the internet: investigation of Swede's internet habits]. Internet Foundation in Sweden, Stockholm. https://2018.svenskarnaochin ternet.se/

Dozza M, Sayer JR, Flannagan C (2013) Understanding driver selfregulating behavior: how does phone use influence vehicle control in real world? Paper presented at the the 2nd international conference on driver distraction and inattention, Gothenburg, Sweden

Elvik R (2011) Effects on accident risk of using mobile phones: problems of meta-analysis when studies are few and bad. Paper presented at the TRB Annual Meeting, Waschington DC

euroFOT (2011) http://www.eurofot-ip.eu/. Accessed 5 Oct 2011

Funkhouser D, Sayer JR (2012) Naturalistic census of cell phone use. Transp Res Rec 2321:1-6. https://doi.org/10.3141/2321-01

George AM, Brown PM, Scholz B, Scott-Parker B, Rickwood D (2018) "I need to skip a song because it sucks": exploring mobile 
phone use while driving among young adults. Transp Res Part F 58:382-391

Glassbrenner D, Ye TJ (2007) Driver cell phone use in 2006-overall results. Department of Transportation, National Highway Safety Administration, Washington, DC

Harari GM, Müller SR, Aung MS, Rentfrow PJ (2017) Smartphone sensing methods for studying behavior in everyday life. Curr Opin Behav Sci 18:83-90

Harrison MA (2011) College students' prevalence and perceptions of text messaging while driving. Accid Anal Prev 43(4):1516-1520. https://doi.org/10.1016/j.aap.2011.03.003

Hickman JS, Hanowski RJ (2012) An assessment of commercial motor vehicle driver distraction using naturalistic driving data. Traffic Injury Prev 13(6):612-619. https://doi.org/10.1080/15389 588.2012.683841

Hickman JS, Hanowski RJ, Bocanegra J (2010) Distraction in commercial trucks and buses: assessing prevalence and risk in conjunction with crashes and near-crashes. Virginia Tech Transportation Institute, Blacksburg

Highway Loss Data Institute (2010) Texting laws and collision claim frequencies, vol 27. Highway LossData Institute Bulletin. http:// www.iihs.org/iihs/topics/t/distracted-driving/hldi-research

Hill L, Rybar J, Styer T, Fram E, Merchant G, Eastman A (2015) Prevalence of and attitudes about distracted driving in college students. Traffic Injury Prev 16(4):362-367. https://doi.org/10.1080/15389 588.2014.949340

Huth V, Brusque C (2014) Drivers' adaptation to mobile phone use: interaction strategies, consequences on driving behaviour and potential impact on road safety. In: Driver adaptation to information and assistance systems, pp 173-196

Järv O, Ahas R, Saluveer E, Derudder B, Witlox F (2012) Mobile phones in a traffic flow: a geographical perspective to evening rush hour traffic analysis using call detail records. PloS One 7(11):e49171

Johnson M, Voas R, Lacey J, McKnight A, Lange J (2004) Living dangerously: driver distraction at high speed. Traffic Injury Prev 5:1-7

Klauer SG, Guo F, Simons-Morton BG, Ouimet MC, Lee SE, Dingus TA (2014) Distracted driving and risk of road crashes among novice and experienced drivers. N Engl J Med 370(1):54-59. https:// doi.org/10.1056/NEJMsa1204142 doi

Kujala T, Mäkelä J (2018) Naturalistic study on the usage of smartphone applications among Finnish drivers. Accid Anal Prev 115:53-61

McCartt AT, Hellinga LA, Bratiman KA (2006) Cell phones and driving: review of research. Traffic Injury Prev 7(2):89-106

National Highway Traffic Safety Administration (2010) Driver electronic device use in 2009. NHTSA ReportDOT HS 811372. NHTSA, Washington. http://www.distraction.gov/download/resea rch-pdf/Driver-Electronic-Device-Use-2009.pdf

Olsen EOM, Shults RA, Eaton DK (2013) Texting while driving and other risky motor vehicle behaviors among US high school students. Pediatrics 131(6):e1708-e1715. https://doi.org/10.1542/ peds.2012-3462

Olson RL, Hanowski RJ, Hickman JS, Bocanegra J (2009) Driver distraction in commercial vehicle operations (No. FMCSARRT-09-042). Federal Motor Carrier Safety Administration, United States.https://rosap.ntl.bts.gov/view/dot/17715

Oren M, Assaf B, Yaniv M (2018) Smartphone based electronic records of naturalistic driver actions. Paper presented at the 6th international conference on driver distraction and inattention, Gothenburg, Sweden
Oviedo-Trespalacios O, Haque MM, King M, Washington S (2017) Effects of road infrastructure and traffic complexity in speed adaptation behaviour of distracted drivers. Accid Anal Prev 101:67-77. https://doi.org/10.1016/j.aap.2017.01.018

Parnell KJ, Stanton NA, Plant KL (2018) Good intentions: drivers' decisions to engage with technology on the road and in a driving simulator. Cogn Technol Work 20(4):597-619

Scott SL (2017) Zendrive crunches 30 billion miles of smartphone data and works with Milliman to build one of the industry's strongest predictive models (white paper). Milliman Inc., Seattle

Simmons SM, Hicks A, Caird JK (2016) Safety-critical event risk associated with cell phone tasks as measured in naturalistic driving studies: a systematic review and meta-analysis. Accid Anal Prev $87: 161-169$

Strayer DL, Drews FA, Johnston WA (2003) Cell phone-induced failures of visual attention during simulated driving. J Exp Psychol 9(1):23

Svenson O, Patten CJ (2005) Mobile phones and driving: a review of contemporary research. Cogn Technol Work 7(3):182-197

Taylor DM, MacBean CE, Das A, Rosli RM (2007) Handheld mobile telephone use among Melbourne drivers. Med J Aust 187(8):432-434

Tivesten E, Dozza M (2015) Driving context influences drivers' decision to engage in visual-manual phone tasks: Evidence from a naturalistic driving study. J Saf Res 53(0):87-96. https://doi. org/10.1016/j.jsr.2015.03.010

Troglauer T, Hels T, Christens PF (2006) Extent and variations in mobile phone use among drivers of heavy vehicles in Denmark. Accid Anal Prev 38(1):105-111. https://doi.org/10.1016/j. aap.2005.07.008

Vanderhaegen F, Carsten O (2017) Can dissonance engineering improve risk analysis of human-machine systems? Springer, New York

Vivoda JM, Eby DW, St. Louis RM, Kostyniuk LP (2008) Cellular phone use while driving at night. Traffic Injury Prev 9(1):37-41. https://doi.org/10.1080/15389580701737603

Wandtner B, Schumacher M, Schmidt EA (2016) The role of selfregulation in the context of driver distraction: a simulator study. Traffic Injury Prev 17(5):472-479. https://doi.org/10.1080/15389 588.2015.1102231

Wang P, Hunter T, Bayen AM, Schechtner K, González MC (2012) Understanding road usage patterns in urban areas. Sci Rep 2:1001

Wang Z, He SY, Leung Y (2018) Applying mobile phone data to travel behaviour research: a literature review. Travel Behav Soc 11:141-155

Wilkinson ML, Brown AL, Moussa I, Day RS (2015) Prevalence and correlates of cell phone use among Texas drivers. Prev Med Rep 2:149-151. https://doi.org/10.1016/j.pmedr.2015.02.010

Young RA (2015) Cell phone conversation and relative crash risk. In: Zheng Y (ed) Encyclopedia of mobile phone behavior. IGI Global, Hershey, pp 1274-1306. https://doi.org/10.4018/978-14666-8239-9.ch102

Zhou R, Yu M, Wang X (2016) Why do drivers use mobile phones while driving? The contribution of compensatory beliefs. PloS One 11(8):e0160288

Publisher's Note Springer Nature remains neutral with regard to jurisdictional claims in published maps and institutional affiliations. 